\title{
Buckling and Post Buckling Behavior for Unsymmetrical Laminates Part I: Curing Cycle
}

\author{
A. Y. Elruby ${ }^{1}$, T. Ahmed ${ }^{2}$, S. Nakhla ${ }^{3 *}$ \\ ${ }^{1} \mathrm{Ph} . \mathrm{D}$. Candidate. ${ }^{2}$ Graduate student and ${ }^{3 *}$ Assistant Professor \\ Dept. of Mechanical Engineering, Faculty of Engineering and Applied Science \\ Memorial University of Newfoundland \\ St. John's, Canada \\ E-mail*: satnakhla@mun.ca
}

\begin{abstract}
This is the first of two companion papers that examine the elastic buckling and post-buckling behavior of thin unsymmetric cross-ply laminates. When cured in a flat mold these panels possess two cylindrical equilibrium configurations. From stability perspective this problem is identified as a bifurcation buckling problem. As explained in literature thermal mismatch between plies and existing geometric imperfections triggered this behavior. Therefore, and according to Koiter it is necessary to measure and account for these geometric imperfections to accurately predict the cured shapes. Since imperfection measurement is challenging and cannot be possible in the stage of design. This work applies a unified finite element methodology based on Koiter's theory to predict the cured shapes. This methodology is consistently applied in commonly used finite element computer codes, ABAQUS, ANSYS and LS-DYNA, and their predictions are compared.
\end{abstract}

Keywords- bistable, unsymmetric, cross-ply, curing, buckling, post-buckling.

\section{INTRODUCTION}

When thin unsymmetric composite laminate is cured in a press or an autoclave, it will develop out-of-plane deformations at room temperature. These deformations are due to mismatch in thermal expansion behavior and elastic properties of laminae within the laminate. Hyer [1] reported the shapes of several families of unsymmetric laminates and observed that the roomtemperature shapes do not always conform to the predictions of classical lamination theory. To justify this mismatch Hamamoto and Hyer [2] measured the cured laminate and reported its lack of thickness uniformity, i.e., thicker in the middle than it is near the edges. The reason for such non-uniform thickness was explained to be caused by resin flow during curing resulting in differences in fiber volume faction from one location to the next within the laminate. Some other factors were also suggested to be responsible for geometric imperfections, such as the handlayup technique in which it is impossible to precisely orient or stack different laminae.

Several solutions reported in literature focused on predicting the cured shapes of unsymmetric cross-ply laminates [3]. The first solution among these was developed by Hyer [4] presenting the extended classical lamination (ECLT) theory based on the Principal of Minimum Total Potential Energy (PMTPE). Predictions obtained from ECLT was limited to unsymmetric square laminates with straight edges. The first finite element solution was originally proposed by Schlecht and Schulte [5] in which they added a subroutine in finite element (FE) code MARC applying so-called backward method to obtain the cured shapes of unsymmetric square cross-ply laminates. Their finite element analysis (FEA) predictions agreed with Hyer's measurements and analysis [1, 4]. The first analytically correct FEA methodology using Abaqus finite element code was initially presented then published by Tawfik et al. $[6,7]$. Their methodology was based on Koiter's theory [8] and their predictions of room temperature cured shapes were in good agreement with Hyer's measurements and analysis [1, 4]. Giddings et al. [8] developed an improved FE model in ANSYS V11.0 to predict the cured shapes of thin unsymmetric laminates. They developed two FE models, the first model was based on 'idealised' nominal ply-thickness which required a temporary force during the initial curing simulation to allow convergence. While the second 'improved model' used optical microscopy, data obtained post curing to account for resin rich areas in the FE simulation. Giddings et al. [8] reported excellent predictions using the 'improved model' and acceptable predictions by the model based on idealised ply-thickness. In summary, to enable FEA to accurately predict the cured shapes of thin unsymmetric laminates one must account for deviations in geometry such as resin rich areas. Meanwhile measuring the specific to certain laminate deviation may not be possible prior to manufacturing. Therefore, an analytical solution based on Koiter's theory provides the potential for accurate predictions prior to manufacturing, e.g. during the design stages.

To this end the current work aimed at providing a general applicability of the proposed methodology of Tawfik et al. [6, 7]. Their proposed methodology which they developed in Abaqus was consistently applied in Ansys and LS-Dyna. Cured shapes of thin unsymmetric laminated as predicted by all $\mathrm{FE}$ codes, ABAQUS, ANSYS and LS-DYNA were compared, and conclusions were provided. 
TABLE II. ELEMENT TYPES IN DIFFERENT FE CODES

\section{METHODOLGY}

\section{A. Problem definition}

Tawfik [10] and Tawfik et al. [6, 7, 11] were pioneers in investigating the shapes of unsymmetric cross-ply laminate under thermal curing stresses using FEA. Based Koiter's theory [8], considering the effect of the geometric imperfections, they developed a FE based methodology for predicting such cured shapes.

Tawfik et al. $[6,7,11]$ implemented their FE methodology in ABAQUS and proved that without geometric imperfection cured shape of an unsymmertic laminate cannot be predicted by FEA accurately. They did an extensive study regarding shape prediction using their FE methodology and finally came up with two distinct useful relations which they named as the temperature-curvature relationship and the design curve.

This current work is focused on presenting a generalized FE based methodology to predict the shapes of unsymmetric crossply laminates under thermal curing load by replicating Tawfik's ABAQUS model in two other commercial FE codes, ANSYS and LS-DYNA, and finally comparing the ANSYS and LSDYNA results with the ABAQUS results.

\section{B. Description of basic FEA model}

The cross-ply unsymmetric laminate used in this model has square geometric configuration and it is a $\left[0_{n} / 90_{n}\right]$ laminate of Hexcel IM7/8551-7 graphite/epoxy prepreg with mechanical properties provided in Table I.

Tawfik [10] conducted the convergence study with all the shell elements available in Abaqus element library and ended with the selection of S4R as the element type and $20 \times 20$ as the mesh size for optimal modeling of this problem in ABAQUS.

For the present work uses shell elements and $20 \times 20$ mesh for modeling. Table II documents the details about the element types used in three different FE codes.

The centre point of the laminate geometry is fixed in all degrees of freedom during the curing cycle. The applied load during curing cycle is a temperature drop with a magnitude of $156{ }^{\circ} \mathrm{C}$. Fig. 1 shows the basic ABAQUS model used for this curing cycle problem.

TABLE I. MECHANICAL PROPERTIES OF MATERIAL AS REPORTED BY TAWFIK [10]

\begin{tabular}{|c|c|c|c|c|c|c|c|}
\hline Material & $\begin{array}{c}\boldsymbol{E}_{\mathbf{1 1}} \\
(\mathbf{G P a})\end{array}$ & $\begin{array}{c}\boldsymbol{E}_{\mathbf{2 2}} \\
(\mathbf{G P a})\end{array}$ & $\begin{array}{c}\boldsymbol{G}_{\mathbf{1 2}} \\
(\mathbf{G P a})\end{array}$ & $\boldsymbol{v}_{\mathbf{1 2}}$ & $\begin{array}{c}\boldsymbol{\alpha}_{\mathbf{1}} \\
\left(\mathbf{1 0}^{-\mathbf{6}} /{ }^{\mathbf{0}} \mathbf{C}\right)\end{array}$ & $\begin{array}{c}\boldsymbol{\alpha}_{\mathbf{2}} \\
\left(\mathbf{1 0}^{-\mathbf{6}} /{ }^{\mathbf{0}} \mathbf{C}\right)\end{array}$ & $\begin{array}{c}\boldsymbol{t} \\
(\boldsymbol{\mu m})\end{array}$ \\
\hline $\begin{array}{c}\text { IM7/8551-7 } \\
\text { graphite/epo } \\
\text { xy prepreg }\end{array}$ & 141.18 & 7.20 & 4.45 & 0.30 & 0.30 & 30.98 & 138.75 \\
\hline
\end{tabular}

\begin{tabular}{|c|c|c|c|c|}
\hline FE code & $\begin{array}{c}\text { Element } \\
\text { name }\end{array}$ & $\begin{array}{c}\text { Element } \\
\text { type }\end{array}$ & $\begin{array}{c}\text { Number } \\
\text { of DOF* }\end{array}$ & Description \\
\hline $\begin{array}{c}\text { ABAQUS } \\
{[12]}\end{array}$ & S4R & $\begin{array}{c}\text { Shell } \\
\text { element }\end{array}$ & 6 & $\begin{array}{c}\text { A four-node general- } \\
\text { purpose finite-membrane- } \\
\text { strain shell with reduced } \\
\text { integration for hourglass } \\
\text { control }\end{array}$ \\
\hline $\begin{array}{c}\text { ANSYS } \\
{[13]}\end{array}$ & Shell 181 & $\begin{array}{c}\text { Shell } \\
\text { element }\end{array}$ & 6 & $\begin{array}{c}\text { A four-node thin to } \\
\text { moderately-thick shell } \\
\text { with both full and reduced } \\
\text { integration schemes }\end{array}$ \\
\hline $\begin{array}{c}\text { LS-DYNA } \\
{[14]}\end{array}$ & Type 16 & $\begin{array}{c}\text { Shell } \\
\text { element }\end{array}$ & 6 & $\begin{array}{c}\text { A four-node fully } \\
\text { integrated thin shell with } \\
\text { assumed strain } \\
\text { interpolation and available } \\
\text { hourglass control option }\end{array}$ \\
\hline
\end{tabular}

*Degrees of freedom
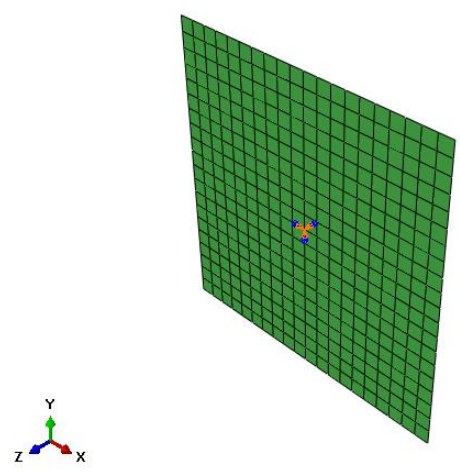

Figure 1. Image of basic model from ABAQUS

\section{Equation and curves presented by Tawfik and Tawfik et al.}

1) The temperature-curvature relationship

Utilizing the concept of geometric imperfection, Tawfik et al. $[6,7,11]$ used their ABAQUS model to predict the bifurcation point or the tendency of retaining cylindrical-like. Two curvatures of two adjacent sides of the square unsymmetric cross-ply laminate ware plotted in a temperature vs. curvature graph, keeping the cure cycle relative temperature along the abscissas and curvatures along the ordinates. The point from which the two curvatures start deviating from each other is the bifurcation point and the graph was named as temperaturecurvature relationship. This deviation of two curvatures of two adjacent sides indicates the tendency of a unsymmetric crossply laminate to retain two different curvatures with bistable behavior while curing. Their ABAQUS analysis predicted the bifurcation point to occur at a relative temperature of $140.60{ }^{\circ} \mathrm{C}$ with a laminate curvature of $0.290 \mathrm{~m}^{-1}$. Curvatures were approximate using (1).

$$
\kappa=\frac{1}{R} \cong \frac{8 d}{C^{2}+4 d^{2}}
$$

where $\kappa$ is the approximated curvature, $R$ is the radius, $d$ is the out-of-plane displacement and $C$ is the chord length as shown in Fig. 2. 


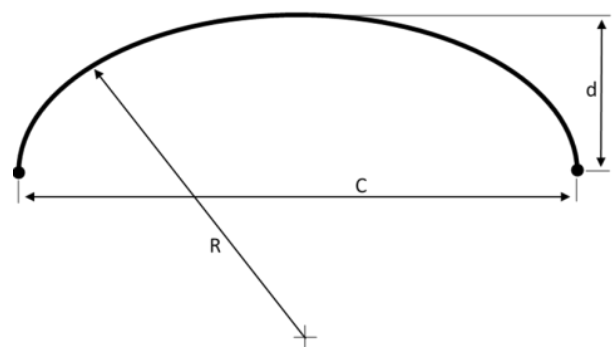

Figure 2. Curvature of laminate

\section{2) The design curve}

Tawfik [10] and Tawfik et al. [6, 7, 11] predicted the out-ofplane deformation and expressed it as the effect of laminate side length-to-thickness ratio. This relationship was named as the design curve while keeping the non-dimensional curvature along the abscissas and non-dimensional side length along the ordinates. This design curve shows that the relative side lengthto-thickness ratio is one of the parameters controlling the panel's bistable behavior and there is a critical value of side length in units of thickness that makes the laminate to have cylindrical-like shape. This non-dimensional critical side length for square $\left[0_{n} / 90_{n}\right]$ laminate was documented as $L_{C}^{*}=82.8$, below which the cured panel assumes a saddle shape and above it the panel is bistable with cylindrical-like equilibrium shapes. They defined the non-dimensional side length and nondimensional curvature as respectively (2) and (3).

$$
\begin{gathered}
L^{*}=\frac{L}{t} \\
\kappa^{*}=\kappa \times L \times \frac{180}{\pi}
\end{gathered}
$$

where $L^{*}$ and $\kappa^{*}$ are non-dimensional side length and nondimensional curvature respectively. While $L, t$ and $\kappa$ are the side length, thickness and curvature of the laminate respectively.

\section{Modelling curing cycle in ABAQUS}

Tawfik [10] and Tawfik et al. [6, 7, 11] presented, in ABAQUS the cylindrical-like cured shapes of an unsymmetric laminate can be easily obtained through three major steps as follows

- Eigenvalue buckling analysis of the perfect geometry using the *BUCKLE option which is also known as buckling analysis.

- Introducing geometric imperfections as a linear superposition of buckling eigenmodes of the perfect geometry using *IMPERFECTION option.

- A geometrically non-linear load-displacement analysis of the imperfect structure using the *STATIC, STABILIZE method which is one kind of post buckling analysis.
Tawfik [10] and Tawfik et al. $[6,7,11]$ stated, one of the major step of their methodology is accounting for geometric imperfection. So, they studied the influence of imperfection size on predicting the bifurcation point and figured out that imperfection in a must for predicting cylindrical-like cured shape and the most suitable imperfection size for this problem is one tenth of the laminate thickness. This current work will also use the same size of imperfection.

Tawfik [10] mentioned about two different procedures available in ABAQUS for solving non-linear systems of equations and among those two, the one which can introduce an artificial damping into the solution is more suitable for problems with local instability and hence enables to capture the cylindrical shape during the curing cycle and in ABAQUS it is available in the name of STABILIZE.

Further for modeling the curing cycle in LS-DYNA and ANSYS Tawfik's three-step methodology will be followed as guideline.

\section{E. Modelling curing cycle in LS-DYNA}

With LS-DYNA cylindrical-like cured shapes of an unsymmetric laminate can be predicted as follows.

- Eigenvalue buckling analysis of the perfect geometry using the *CONTROL_IMPLICIT_EIGENVALUE [14] option.

- Introducing geometric imperfection as a linear superposition of buckling eigenmodes of the perfect geometry using *PERTURBATION_NODE [14] option.

- A geometrically non-linear load-displacement analysis of the imperfect structure using the *CONTROL_IMPLICIT_STABILIZATION [14] option.

ABAQUS creates the buckling results in normalized form but in LS-DYNA eigen buckling analysis results are not normalized. So, this should be taken into consideration while selecting the value of the scale factor.

\section{F. Modelling curing cycle in ANSYS}

Unlike ABAQUS and LS-DYNA solving this current problem in ANSYS requires following four steps:

- Static analysis step to get an initial deformation that is going to be used in the Eigen buckling analysis.

- Eigen buckling analysis step is used to generate the Eigen modes for the model based on the applied thermal load in the static analysis step using any available eigen solver i.e.; SUBOPT [13].

- Based on extracted Eigen mode shapes the geometry of the model is to be perturbed using a required imperfection value. The command UPCOORD [13] is used by multiplying a scale factor of imperfections to a specified step results.

- The last step is to solve a non-linear analysis for the imperfect geometry obtained from the previous step using STABILIZE [13] command. 
Like LS-DYNA eigen buckling analysis results in ANSYS are not normalized by default. So, this should be taken into consideration while selecting the value of the scale factor.

\section{G. A unified Finite Element Analysis methodology}

Curing of a laminate is a locally instable nonlinear problem which is highly imperfection sensitive. So, modeling the curing cycle in FEA requires solving a linear perturbation associated with geometric imperfection and a nonlinear load-displacement analysis in a row [10]. Implementation of modeling technique proposed by Tawfik in these three FE codes can be summarized as:

Modeling a curing cycle in any FEA code requires three available options.

- An eigenvalue solver for buckling analysis to get the eigenmodes.

- An option to introduce a geometric imperfection into the structure.

- An implicit non-linear solver that can introduce an artificial damping into the solution to make this locally instable problem to capture the cylindrical-like shape.

Tawfik [10] first came up with this three-step Finite Element Analysis methodology and can be used as a unified guideline for modelling curing cycle in any FEA as LS-DYNA and ANSYS.

\section{RESULTS AND DISCUSSION}

Tawfik [10] did an extensive study to figure out the effect of geometric imperfection on predicting the cured shapes of unsymmetric laminates and proved using ABAQUS that without any imposed geometric imperfection FEA cannot capture the cylindrical-like shape and predicts the saddle shape. Fig. 3 is the predicted saddle shape by ABAQUS in absence of imperfection and Fig. 4 is the cylindrical-like shape in the presence of imperfection.

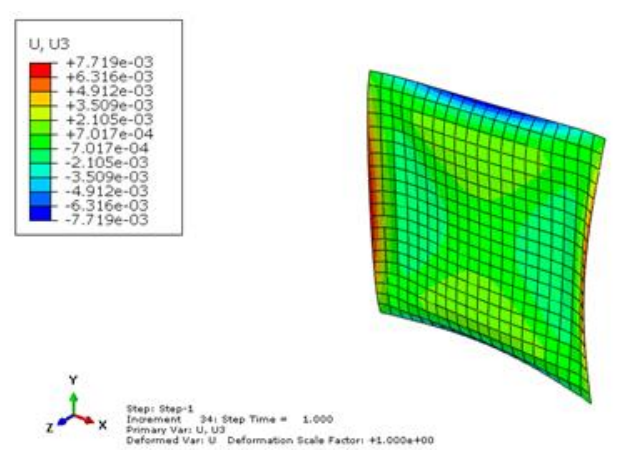

Figure 3. Saddle shape predicted by ABAQUS in absence of geometric imperfection

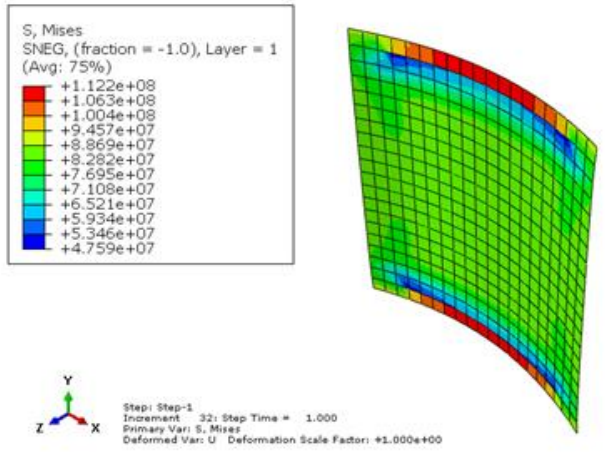

Figure 4. Cylindrical-like shape predicted by ABAQUS in presence of geometric imperfection

With the same size of imperfection suggested by Tawfik [10] and without imperfection LS-DYNA and ANSYS both predict cylindrical-like and saddle shape respectively as ABAQUS does. Fig. 5 is the predicted saddle shape by LSDYNA in absence of imperfection and Fig. 6 is the predicted cylindrical-like shape in presence of imperfection. Fig. 7 and Fig. 8 respectively represents the saddle and cylindrical-like shape predicted by ANSYS.

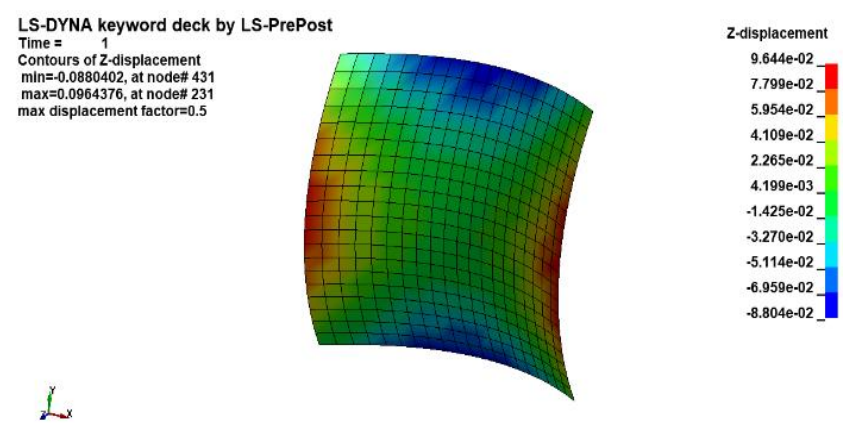

Figure 5. Saddle shape predicted by LS-DYNA in absence of geometric imperfection
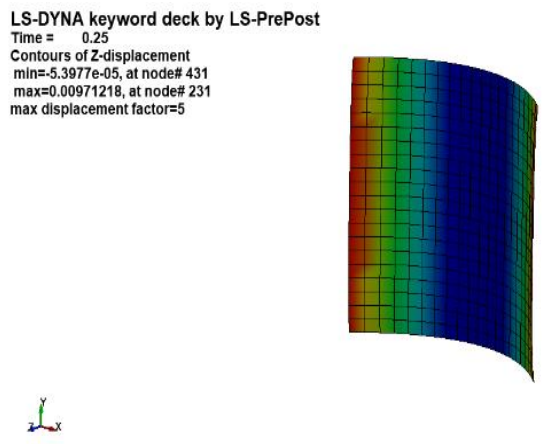

Z-displacement $9.712 \mathrm{e}-03$ $8.736 \mathrm{e}-03$ $6.782 \mathrm{e}-03$ $4.829 \mathrm{e}-03$ $3.852 \mathrm{e}-03$ $2.876 \mathrm{e}-03$ $1.899 \mathrm{e}-03$ $9.226 \mathrm{e}-04$ $-5.398 \mathrm{e}-05$

Figure 6. Cylindrical-like shape predicted by LS-DYNA in presence of geometric imperfection 


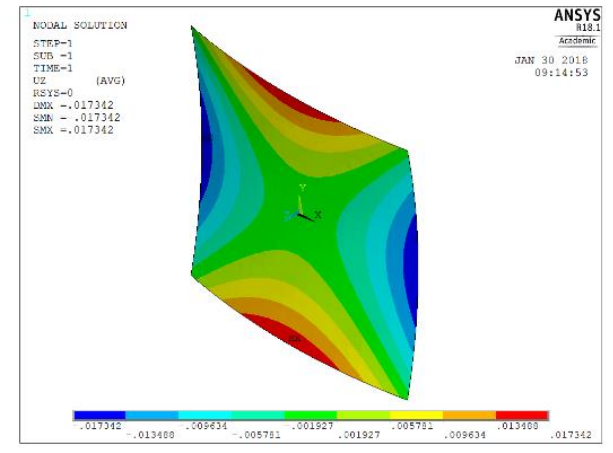

Figure 7. Saddle shape predicted by ANSYS in absence of geometric imperfection

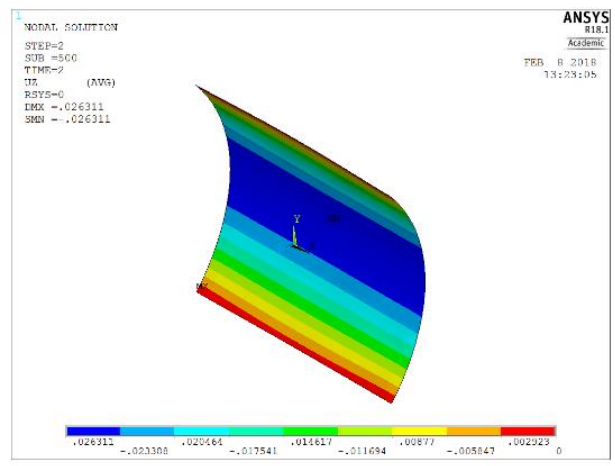

Figure 8. Cylindrical-like shape predicted by ANSYS in presence of geometric imperfection

To compare the ABAQUS, ANSYS and LS-DYNA results, both the temperature-curvature relationship and the design curve from these three codes have been plotted and compared with each other.

To plot the temperature-curvature relation Tawfik's [10] results in ABAQUS were reiterated in ABAQUS, ANSYS and LS-DYNA while recording curvatures of both sides and thermal load at every time increment. Fig. 9 shows the temperature curvature relation from ABAQUS, ANSYS and LS-DYNA for square $\left[0_{\mathrm{n}} / 90_{\mathrm{n}}\right]_{\mathrm{T}}$ laminate of Hexcel IM7/8551-7 graphite/epoxy prepreg in the same graph. The figure also shows the results from ABAQUS, ANSYS and LS-DYNA are in an excellent agreement and the bifurcation temperature prediction from these three FE codes is almost the same.

To plot the design curve the side length of the square $\left[0_{n} / 90_{n}\right]_{T}$ laminates was varied from $0.01 \mathrm{~m}$ to $0.15 \mathrm{~m}$ keeping the laminate thickness and layup unchanged while recording the corresponding curvatures of the two sides of the laminate at the end of the curing cycle. Fig. 9 Shows the design curve from ABAQUS, ANSYS and LS-DYNA for square $\left[0_{n} / 90_{n}\right]_{T}$ laminate of Hexcel IM7/8551-7 graphite/epoxy prepreg in the same graph and it also shows the results from ABAQUS, ANSYS and LS-DYNA are in an excellent agreement and the critical side length prediction from these three FEA codes is almost the same.

A good agreement of ANSYS and LS-DYNA results with the ABAQUS result makes Tawfik's three-step FE based methodology unified.

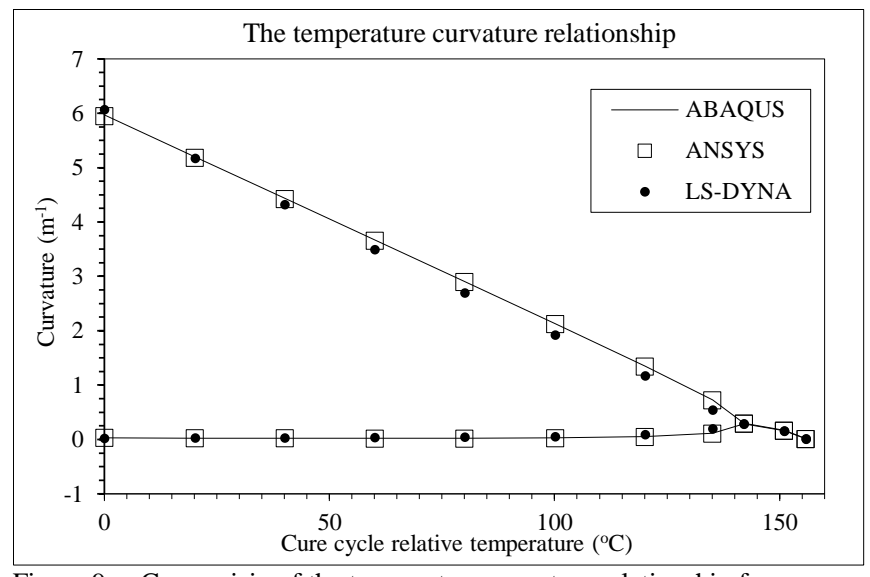

Figure 9. Comparisin of the temperature curvature relationship for square $\left[0_{n} / 90_{n}\right]_{T}$ laminate of Hexcel IM7/8551-7 graphite/epoxy prepreg from ABAQUS, ANSYS and LS-DYNA.

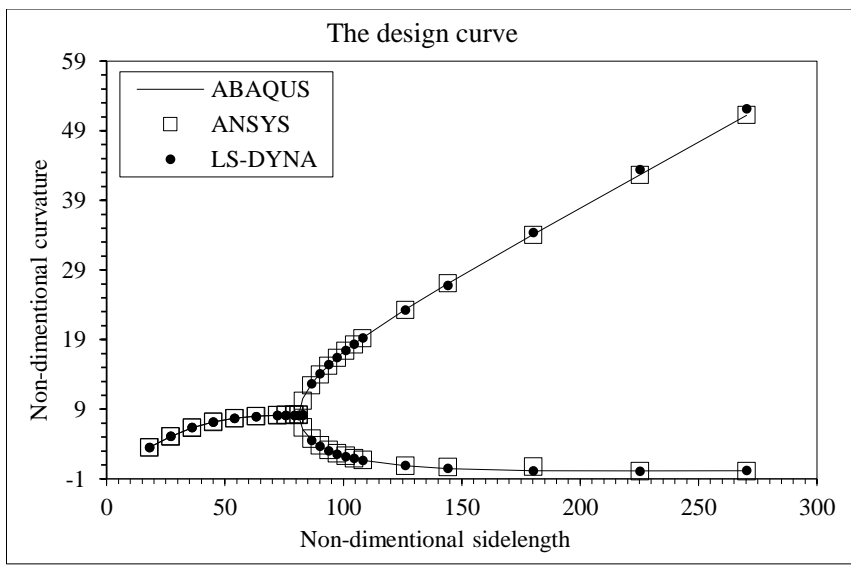

Figure 10.Comparison of the design curve for square $\left[0_{n} / 90_{n}\right]_{T}$ laminate from ABAQUS, ANSYS and LS-DYNA

\section{CONCLUSION}

This work addressed the buckling behavior of thin unsymmetric laminates and their out-of-plane cured shapes. An analytically correct methodology is obtained from literature and applied in commonly used finite element computer codes, Abaqus, Ansys and LS-Dyna. Predicted out-of-plane cured shapes of thin unsymmetric cross-ply laminated were compared and results from all $\mathrm{FE}$ codes were found in excellent agreement. Therefore, the currently used analytically correct methodology proved its generality and applicability in commonly used FE software codes.

\section{REFERENCES}

[1] Hyer, M.W. (1981). "Some Observations on the Cured Shapes of Thin Unsymmetric Laminates", Vol. 15, 175-194, Journal of Composite Materials.

[2] Hamamoto, A. and Hyer, M.W. (1987) "Non-linear Temperature-curvature Relationships for Unsymmetric Graphite-Epoxy Laminates", Vol. 23, 
919-935, International Journal of Solids and Structures.

[3] Emam SA, Inman DJ. A review on bistable composite laminates for morphing and energy harvesting. Applied Mechanics Reviews. 2015 Nov 1;67(6):060803.

[4] Hyer, M.W. (1981) "Calculations of the Roomtemperature Shapes of Unsymmetric Laminates", Vol. 15, 296-310, Journal of Composite Materials

[5] Schlecht M, Schulte K. Advanced calculation of the room-temperature shapes of unsymmetric laminates. Journal of Composite Materials. 1999 Aug;33(16):1472-90.

[6] S. Tawfik, X. Tan, S. Ozbay and E. Armanios, "Modeling of anticlastic stability in elastically tailored composites," in Proceedings of 20th annual technical ASC conference, Drexel University, Philadelphia, Pennsylvania, 2005.

[7] S. Tawfik, X. Tan, S. Ozbay and E. Armanios, "Anticlastic Stability Modeling for Cross-ply Composites," Journal of Composite Materials, vol. 41, no. 11, pp. 1325-1338, 2006.
[8] Koiter WT. On the stability of elastic equilibrium, Ph.D. Thesis, 1945, Polytechnic Institute Delft, NASA TTF-10833; 1967.

[9] Giddings PF, Bowen CR, Salo AI, Kim HA, Ive A. Bistable composite laminates: effects of laminate composition on cured shape and response to thermal load. Composite Structures. 2010 Aug 1;92(9):22205.

[10] S. Tawfik, Stability and morphing characteristics of bistable composite laminates. Georgia Institute of Technology, 2008.

[11] S. Tawfik, D. S. Dancila and E. Armanios, "Planform Effects Upon the Bistable Response of Cross-Ply Composite Shells," Composites Part A: Applied Science and Manufacturing, vol. 42, no. 7, pp. 825833, 2011.

[12] Simulia, D. S. (2014). Abaqus 6.14 user manual. Providence, RI, USA: DS SIMULIA Corp.

[13] Manual, A. U. S. Version 16.2, 2015. ANSYS Inc., Canonsburg, USA.

[14] Manual, L. D. K. U. S., \& Volume, I. (2013). Version 971. Livermore Software Technology Corporation, 7374 